\title{
Preparing for the influenza pandemic: remember its ally the pneumococcus
}

When the BBC reported the findings of the analysis which showed that influenza immunisation was of little if any value in the fit, independently-living elderly, I was appalled at the imbalance of the discussion. It seems Charles heard it too, and our mutual disdain leads to two conversations the first of which I record below.

'Although medical science advances into territories thought impossible only one or two decades ago, I cannot help being struck by occasional episodes where innate conservatism seems the order of the day.'

'What's the explanation?' I asked.

'Medicine is not pure science. Social and ethical trends and perceptions influence the direction and speed of change and may retard it. And don't dismiss the effect of politics!'

'What made you raise the subject? Is there a recent example?'

'Yes there is and I mention it because it started a train of thought.'

I expressed interest, 'What was it Charles?'

'I heard the about the efficacy of influenza immunisation in the fit elderly population. Speaking as one of them, to my mind, I am the last person to whom it should be offered.'

'Why, Charles?'

'Presumably even after allowing for the variation in strains, I am partially immune as a result of a lifetimes exposure, and like many of us I have not fallen ill with any of the recent epidemics. I am less likely to be exposed now that I do little work. Not only am I a fit and healthy survivor with reduced risk of infection, but I also no longer earn my living or have a family to support.'

'That should not influence your right to treatment, Charles!' I said, but was not surprised by the reply.

'I think you know that despite my age I hold the view that unless resources are unlimited, equity demands otherwise. Be that as it may, however, surely common sense suggests that fit survivors with a reduced potential exposure to infection are the least likely to benefit from an immunisation programme.'
'I must admit there is something in that' I replied.

'As you might have guessed I was pleased when my prejudices and armchair science were vindicated when it was announced that the exercise was a waste of time, but I was horrified by the way the story was handled. The proponents were given a hearing but the Department of Health turned down the opportunity to contribute and were replaced by anecdotes from an elderly patient.'

'You can hardly blame the BBC for the department not turning up!'

'No, but the patient must have been very convincing to those who started with a prior conviction that it must work. The department's reaction in avoiding the issue was, in my mind, an example of conservatism. In this case I am sure it was face-saving! Who wants to admit they have been advocating and promoting a programme to very little benefit?'

'Did the train of thought go further?' I asked, confident that he had something up his sleeve.

'Yes, Coe, you've guessed right!' Charles then continued. 'I thought of planning for the predicted major influenza epidemic. I hope the department is able to think radically and not be bound by past practices and current social taboos.'

'What do you mean?'

'Forget about trying to prevent it and ...'

I looked taken aback.

'Yes! The virus is not stable enough for immunisation to eradicate it from the population. I am told that the sufferer becomes infectious early, often before symptoms, so isolation cannot work for the individual or more importantly for the nation. Planning for and supervision of such activities as preventing entry by travel restrictions would be a waste of time. At best such measures might delay the problem and at worst the eventual pattern of spread may be more rapid and so more difficult to manage.' 
'Fair enough, but how would you manage the pandemic when it reaches our shores?'

'Remember reserved occupations and essential industries during the war? Follow this successful precedent and be realistic and not "politically correct" in setting priorities.'

'What should they be, Charles?'

'The first should be to identify those most valuable to society who will keep the ship sailing. The second is to identify the most susceptible and act accordingly and the third is to radically consider which measures are most likely to prevent death. In the first category, health professionals must come top, followed by parents of young children, and then those who provide our essential needs, such as the basic food industry.'

'What about politicians and civil servants?'

'Those directly involved should have the courage, however antagonistic the press, to say "First save ourselves is the correct policy. This is morally right as we have a job to do!"”

'On the same lines turning to the second category, I suppose you would argue that those who proved susceptible in previous epidemics - young adults, small children and the frail elderly should have preference?'

'Yes and in that order, but why frail elderly, is it not frailty rather than age that counts?'

'Touché! But what about the approach to treatment?'

'I would certainly spend more resources on the development and stockpiling of ameliorating drugs than on preparing for immunisation the success of which must depend on the ability to spot the rogue mutation and prepare enough vaccine in time; something that can never be guaranteed.' He paused for thought and then asked, 'Coe, what actually kills people? Wasn't it the Staphylococcus aureus in the 1918 epidemic?'

'That is always said to be the case and is probably at least partially true, though I am sure lots of people died of the flu itself. Nevertheless some recent studies have shown that even with antibiotics, the currently rare combination with staphylococcal infection is potentially $100 \%$ fatal. Perhaps more relevant, over $50 \%$ were reported to have died with the commoner pneumococcal combination.'

'And these were previously fit young adults?'

'Some of them at least.'

'And the pneumococcus still kills the occasional young adult outside influenza epidemics?'

'Yes.'
'And pneumococci do not mutate like the influenza virus?'

'There does tend to be some variation, but not sufficient to make long-term immunisation useless, after all it is being introduced for babies with meningitis in mind.'

He smiled and said, 'You see what I am driving at?'

'I guess, Charles, that you are suggesting that we useless old buffers should be passed by, and the resources allocated for immunisation switched away from the fit elderly to fit young adults, and from influenza to pneumococcus, in anticipation of the pandemic and for any incidental benefit.'

'Got it in one, Coe!'

One might not agree with Charles's views on equity, but does that not make some medical sense as well?

Coemgenus 